\title{
LA TRADICIÓN COMO MODO DE ADQUIRIR EL DOMINIO EN EL DERECHO ROMANO, EN EL COMÚN Y EN EL IUSNATURALISMO Y SU DESTINO EN LOS DERECHOS PATRIOS DE LA AMÉRICA ESPAÑOLA*
}

\author{
TRADITION AS A MODE OF ACQUIRING OWNERSHIP IN ROMAN, \\ COMMON AND NATURAL LAW AND ITS FATE IN VERNACULAR LAW \\ SYSTEMS OF SPANISH-AMERICA
}

\section{Alejandro GuZmán Brito *}

\begin{abstract}
RESUMEN: La tradición, como modo de adquirir, consistente en la entrega de una cosa fundada en una convención traslaticia, fue diseñada en el Derecho Romano clásico. Los juristas medievales mantuvieron ese diseño, con los cuales pasó al derecho común europeo y al código castellano de las Partidas, a impulso del cual fue trasladado a las Indias españolas. En Francia, sin embargo, el Code Civil abolió el modo de adquirir denominado tradición y la reemplazó por el efecto adquisitivo de la convención traslaticia. El nuevo dogma fue recibido por algunos códigos europeos, como el de Cerdeña y de Italia, pero no por todos. En la codificación del derecho en los nuevos Estados cuyos territorios habían pertenecido a la monarquía española, el dogma francés fue recibido por aquellos cuerpos legales que resultaron intensamente influidos por el código francés; pero en los códigos de Perú y de Chile se conservó el dogma romano. La influencia del código chileno en varios códigos de países de Hispanoamérica hizo que la tradición se mantuviera vigente en ellos hasta el día de hoy.
\end{abstract}

Palabras clave: Modos de adquirir, Tradición, Convención traslaticia del dominio, Adquisición del dominio por convención.

ABSTRACT: The tradition, as ownership's acquisition, involving the delivery of a thing based on a transfer convention, was designed in the classic Roman Law. The medieval jurists maintained that design, which became the European common law and Castilian code of the Partidas, impulse which was transferred in the law of the Spanish Indies. In France, however, the Civil Code abolished the tradition as ownership's acquisition and replaced by purchasing the convention involving transfer effect. The new dogma was received for some European codes, such as Sardinia and Italy, but not all. In the codification of the new territories which had belonged to the Spanish Monarchy, French dogma was received by those legal bodies that were heavily influenced by the French code, but the codes of Peru and Chile was preserved the Roman dogma. The influence of the Chilean code in several countries of Latin America's codes made the tradition to remain current in them until today.

Key words: Modes of Acquisition, Tradition, Convention that Translates Ownership, Ownership's Acquisition by Convention.

\footnotetext{
Profesor de la Facultad de Derecho de la Pontificia Universidad Católica de Valparaíso. Avenida Brasil 2950, Valparaíso, Chile.
} 


\section{LA TRADICIÓN EN EL DERECHO ROMANO}

1. Uno de los temas relevantes de la dogmática del derecho civil de todos los tiempos es el de los que llamamos "modos de adquirir el dominio", entre los cuales la tradición destaca con perfiles muy nítidos. Su contextura quedó afinada en el Derecho Romano clásico. La tradición se identifica con el modo de la transferencia de cosas entre vivos y primordialmente consiste en la entrega de aquellas por el transferente al adquirente, vale decir, en el traspaso físico de una cosa por uno a otro, de donde que obedezca a la categoría de los actos reales y ofrezca estructura posesoria, porque el que recibe la cosa lo que primariamente adquiere es su posesión; mas, cumplidos que hayan sido ciertos presupuestos y requisitos, el acto funciona, además, como modo de adquirir la propiedad.

En el derecho romano clásico, la tradición es el modo de la transferencia entre vivos de las res nec mancipi; estas son todas las que no pertenezcan al catálogo típico de las res mancipi, que son: los fundos itálicos, los esclavos, los animales de tiro y carga, como los caballos, los asnos, los bueyes o las mulas, y las servidumbres de los predios rústicos. Su transferencia entre vivos solo puede tener lugar merced a un acto solemne, que puede ser una mancipatio o una in iure cessio. Las demás cosas son nec mancipi y se transfieren, pues, mediante traditio: el dinero, el vino, el aceite, los frutos naturales como el trigo y muchos otros, el mobiliario de las casas, los animales que no sean de tiro y carga, como los perros, los gatos, las ovejas, los cerdos, las cabras y tantos otros, las armas, los instrumentos de artesanía de toda clases, y las artesanías mismas, etcétera.

El carácter de res nec mancipi que debe tener la cosa que se hace objeto de una tradición es uno de sus presupuestos; el otro es que el tradente sea dueño civil de la cosa que entrega. Además, deben concurrir dos requisitos que conforman el acto: i) una iusta causa traditionis, como compraventa, donación, pago, dote o crédito $^{2}$; y ii) la entrega material de la cosa. Interviniendo los dos presupuestos y los dos requisitos, el que recibe la cosa adquiere su posesión y su dominio. Cuando concurren ambos requisitos, pero falla alguno de los presupuestos, el que recibe la cosa solo adquiere la posesión y menester es que, con base en ella, posteriormente tenga lugar la usucapión para que adquiera el dominio. Si falla el requisito de la iusta causa traditionis, la entrega no permite adquirir ni la posesión ni el dominio, y solo da lugar a la mera tenencia. De hecho, lo que entonces ocurre es que operó una causa no adquisitiva, como arrendamiento, comodato, prenda o depósito y, por cierto, no es posible la usucapión. Apenas debe decirse que cuando falla el requisito material de la entrega, por mucho que comparezcan los dos presupuestos y el requisito de la iusta causa, ciertamente no hay tradición ni adquisición posesoria ni dominical. Por último, cabe destacar que las causas de la tradición, aunque justifican la adquisición dominical no la

\footnotetext{
1 Para la tradición en el derecho romano, me permito reenviar a: GUZMÁn BRITO (2013) I, \$ 129, pp. 631-655. Últimamente: Romeo (2010), casi enteramente dedicado a la tradición en el derecho romano, con abundante literatura; VACCA (2013) pp. 775-804.

2 Dig. 41,1,31 (Paul, 31a ed.): "Nunquam nuda traditio transfert dominium, sed ita, si venditio aut aliqua iusta causa praecesserit propter quam traditio sequeretur" ("La nuda tradición jamás transfiere el dominio sino cuando una venta o alguna otra justa causa precediera, en razón la cual la tradición haya de seguir”). Lo mismo dice GAIUS, Instit. 2, 20.
} 
generan ellas mismas, como se ve óptimamente en el caso de la compraventa, sino merced a la intervención de la entrega, que constituye la base material de todo el modo. Las causas dominicales de la tradición, pues, por sí mismas son capaces únicamente de producir efectos obligacionales, como se ve de nuevo en el caso de la compraventa, o no producen efecto alguno, como ocurre en el evento de la causa solvendi o de la causa credendi y en otros.

Estos son los perfiles fundamentales de la traditio romano-clásica. En el Corpus iuris civilis, puesto que hacia la época de Justiniano la distinción de las cosas en mancipi y nec mancipi había desaparecido del horizonte, lo mismo que los antiguos actos solemnes para adquirir las primeras, vale decir, las antes mencionadas mancipatio e in iure cessio, la traditio permaneció como el único modo de transferencia de las cosas entre vivos, tanto para muebles como inmuebles.

2. La existencia de un modo de adquirir formal, como la mancipatio y la in iure cessio para las res mancipi en las época arcaica y clásica, y real como la traditio para las res nec mancipi en todas las épocas, es inequívocamente indicativa del pensamiento romano dirigido a excluir, por un lado, que el mero consentimiento resultara suficiente para transferir el dominio entre vivos y a exigir, por otro, un acto adicional, destinado a dar publicidad a la adquisición, como fueron la solemnidad o la entrega, según el tipo de cosas de que se tratara. La posterior desaparición de los modos solemnes no atrajo la consecuencia de que ahora el consentimiento cubriera el vacío dejado por ellos, sino, al revés, de que ese vacío fuese cubierto por la tradición, que entonces, como quedó advertido, se convirtió en el modo general de transferir entre vivos; con ello quedó ratificado el pensamiento clásico, que por boca de Diocleciano y Maximiano fue reafirmado ya en los comienzos mismo de la época postclásica mediante el siguiente rescripto conservado en el Codex Iustinianus: "Imperatores Diocletianus et Maximianus AA. et CC. Martiali. Traditionibus et usucapionibus dominia rerum, non nudis pactis transferuntur" 3 . Por lo demás, la dogmática romana sobre la tradición, precedentemente expuesta, hubo de quedar sintetizada en las Institutiones de Justiniano con estas palabras: "Per traditionem quoque iure naturali res nobis adquiruntur: nibil enim tam conveniens est naturali aequitati, quam voluntatem domini, volentis rem suam in alium transferre, ratam haberi. Et ideo cuiuscumque generis sit corporalis res, tradi potest et a domino tradita alienatur [...]" ${ }^{4}$. En este texto se percibe el resultado del derecho postclásico consistente en hacer aplicable la tradición a toda clase de cosas corporales; también queda claro ahí que la tradición consiste en una entrega y que el tradente debe ser su dueño para hacer posible la enajenación. Por lo que a la iusta causa atañe, el texto que sigue de las Insti-

\footnotetext{
3 Cod. Iust. 2, 3, 20: "Los emperadores Diocleciano y Maximiano, augustos y cónsules, a Marcial. El dominio de las cosas se transfiere por las tradiciones y las usucapiones, no por nudos pactos".

4 Iust. Inst. 2, 40: “También por derecho natural adquirimos el dominio de las cosas merced a la tradición, pues nada es tan conveniente a la equidad natural que tener por válida la voluntad del dueño que quiere transferir una cosa suya a otro. Y por esto una cosa corporal de cualquier género que sea puede ser objeto de tradición y entregada que sea por el dueño es alienada [...]”.
} 
tutiones se encarga de ponerla de manifiesto: "Sed si quidem ex causa donationis aut dotis aut qualibet alia ex causa tradantur, sine dubio transferentur [...]"5.

\section{LA CONSERVACIÓN DE LA DOCTRINA ROMANA SOBRE LA TRADICIÓN EN EL DERECHO COMÚN}

La doctrina romana sobre la tradición fue sustancialmente acogida por los doctores glosadores y comentaristas de la Edad Media ${ }^{6}$. Ellos, pues, ratificaron el principio romano de que las cosas no pueden ser transferidas entre vivos por una mera convención si no interviene una tradición. Por todos, podemos citar a Bartolo al respecto: "dominium alicuius rei ex simplici conventione non transfertur absque traditione" 7 .

Puesto que los juristas romanos solían denominar causae acquisitionis a los que llamamos "modos de adquirir"; y uno de estos, la traditio, como vimos, entre sus requisitos tiene el de existir una causa traditionis, para evitar la confusión de lenguaje entre la traditio como causa acquisitionis y uno de sus requisitos, la causa traditionis, los doctores medievales distinguieron en la tradición una causa proxima del dominio, que es la tradición misma en cuanto modo de adquirir (causa acquirendi), y una causa remota que es la causa traditionis, a la que también solían denominar titulus ${ }^{8}$. Esta distinción es el origen del dogma del "título" y "modo", que algunos autores modernos hicieron exceder a la tradición y generalizaron para todas las adquisiciones dominicales ${ }^{9}$ y que aún en nuestros días se lo ve defendido entre algunos autores.

\section{EN ESPECIAL, LA TRADICIÓN EN LAS “PARTIDAS" DE ALFONSO X10}

No es, pues, extraño que las Partidas hayan recogido sin alteraciones la dogmática romana sobre la tradición, en la versión de los glosadores, que en ese cuerpo legal aparece denominada como "apoderamiento". En Part. III, tít. 28ㅇ ley $46^{\mathrm{a}}$ encontramos la siguiente descripción: "Apoderan unos omes a otros en sus cosas vendiendo gelas, o dando gelas en dote, $o$ en otra manera, o cambiando las, o por alguna otra derecha razón. E porende dezimos que por tal apoderamiento como este que faga un ome a otro de su cosa, o que lo faga otro alguno por su

\footnotetext{
5 Iust. Inst. 2,41: "Pero, por lo demás, si se hace la tradición por causa de donación o de dote o por cualquiera otra causa, sin duda se transfiere [la cosa] [...]”.

6 Para la doctrina medieval de la tradición, véanse: Busi (1937) pp. 33-48; BeSTA (1964) pp. 157-158; GoRDON (1970) pp. $97-135$ (glosadores) y 136-158 (comentaristas); Birocchi (1991) pp. 139-167; SCHRAGE (2003), pp. 916-944.

7 Por todos: Bartolo a Sassoferrato (1526/1996), VII, fol. 53 v: "El dominio de alguna cosa no se transfiere por una simple convención sin tradición”. Lo mismo en Baldus degli Ubaldis (1599/2004), V, fol. 107 (por error 109).

8 Sobre el punto, véase: Busi (1937) pp. 34-37.

9 Acerca de esta doctrina, puede verse: Hoffmann (1873) pp. 3-42. Este trabajo se funda en una extensa colección de fuentes, y ello permite prescindir de su antigüedad.

10 La literatura es escasa; véase: LaLinde (1978) pp. 748-751; LeVagGI (1982) pp. 91-93; LeVAGGI (1987) pp. 198-200.
} 
mandado, que passa el señorio dela cosa a aquel a quien apoderasse della"11. Se observará que en este texto la expresión "derecha razón” traduce la latina "iusta causa", de las cuales aparecen aludidas la venta, la dote y el cambio o permuta. Las Partidas regulan el requisito de la entrega, que en su forma más genuina, esto es, en la de la entrega mano a mano, denomina "apoderamiento corporal"12. La regla general aparece sentada en Part. III, tít. 28o ley 47aa, en donde la entrega material queda supuesta: "Otrozi dezimos que por todas aquellas razones, o maneras que passa la tenencia delas cosas delos unos omes alos otros, maguer non sean apoderados dellas corporalmente, según dize en el titulo que fabla de la manera en que puede ome ganar o perder tenencia de las cosas a aquellos a quien son vendidas, o cambiadas, o dadas en dote, o en otra manera, o las han de aver por alguna razón derecha, como quier que delas cosas non fuesen apoderados corporalmente". Porque, salvo en el caso de la "traditio brevi manu", el texto alfonsino trata de las entregas a propósito de los modos de adquirir la posesión, en el título $30^{\circ}$. Ahí, en efecto, se describen las varias maneras de entrega que se remontan al Derecho Romano y a que los medievales impusieron nombres técnicos: i) la "traditio longa manu"13, (ii) la "traditio clavium"14, iii) la traditio chartae o litterae ${ }^{15}$, y iv) el constitutum possessorium ${ }^{16}$, a las que se agrega, como quedó adelantado, v) la "traditio brevi manu"17.

En exposiciones modernas del derecho castellano, cuando llega el momento de tratar de los modos de adquirir el dominio, entre ellos queda incluida, por cierto, la tradición que aparece expuesta de acuerdo con las reglas contenidas en las Partidas. Entre otros, es el caso de las Instituciones de Jordán de Asso y de Manuel y Rodríguez ${ }^{18}$ y, más tardíamente, del Febrero novísimo de Eugenio Tapia ${ }^{19}$, pero también de muchos otros.

Por lo demás, la persistencia en exigir la tradición fue una constante en el derecho común, vale decir, en todos los países europeos ${ }^{20}$, así que Casilla no fue una isla al respecto.

\section{LA TRADICIÓN EN EL DERECHO INDIANO}

En Indias no hallamos mudanzas en el régimen de la tradición establecido por las Partidas, así que, en realidad, como en tantas otras materias, el derecho indiano de la tra-

${ }^{11}$ Cfr. Part. V, 5, 50, en donde se considera la hipótesis de haber alguien vendido dos veces una misma cosa a distintas personas en tiempos sucesivos; y se la soluciona con la atribución del dominio de la cosa a quien de los dos primeramente hubiera sido entregada; lo cual es una aplicación del principio romano. Edición: Las siete Partida del sabio rey don Alonso el nono nuevamente glosadas por el licenciado Gregorio López del Consejo Real de Indias de Su Majestad (1555).

${ }^{12}$ Part. III, tít. $19^{\circ}$, ley $47^{\text {a }}$.

${ }_{13}$ Part. III, tít. $30^{\circ}$, ley $5^{\mathrm{a}}$.

${ }^{14}$ Part. III, tít. $30^{\circ}$, ley $7^{\mathrm{a}}$.

15 Part. III, tít. $30^{\circ}$, ley $8^{\text {a. }}$.

16 Part. III, tít. $30^{\circ}$, ley $9^{\mathrm{a}}$.

17 Part. III, tít. 28º ley $47^{\mathrm{a}}$.

18 Jordán de Asso, del Río, Rodríguez (1771/1792), lib. II, tít. II [por errata señalado como V], cap. 11º: De la tradición y sus especies, pp. 102.

19 TAPIA (1828), lib. II, tít. $1^{\circ}$, cap. 4º, núm. 10, I, pp. 304-305.

${ }^{20}$ Un panorama general de la tradición en el derecho común en: CorNG (1996) I, $₫ 56$, pp. 383-391. Véase también: ZWALVE y SiRKS (2012) pp. 268-271. 
dición resultó ser el establecida en ese viejo cuerpo medieval de leyes, como consecuencia de aplicarse la ley sobre fuentes del derecho en Indias, consistente en la real cédula de 1530 dada por Carlos V, en la cual se mandaba que, en defecto de norma especial emitida para las Indias, rigieran ahí las leyes de Castilla en conformidad con la Ley I de Toro, lo cual significaba aplicar las Partidas aunque no fueren usadas ni guardadas ${ }^{21}$, si no había norma sobre la materia en los ordenamientos, pragmáticas, recopilaciones y fueros vigentes en Castilla. En la citada Ley de Toro, la posibilidad de regir las fuentes indicadas relegaba las Partidas a un tercer lugar; pero, como es sabido, en materia de derecho privado, y el de la tradición no constituyó excepción, la legislación localizada en lugar preeminente en el orden de prelación de hecho no podía recibir aplicación porque no la trataba, y de esta forma se llegaba rápidamente a las Partidas en calidad de fuente supletoria que en la práctica era la principal.

Bien lo confirma una tardía obra de derecho castellano e indiano, como las Instituciones de derecho real de Castilla e Indias de José María Álvarez, en al cual, llegado el momento de tratar de los modos de adquirir, se enumera, por supuesto, la tradición y se la expone según el derecho pertinente contenido en las Partidas ${ }^{22}$, por más que en aquel autor la influencia iusnaturalista se haga sentir a través de Johannes Heineccius, cuyos Elementa iuris naturae et gentium son citados muchas veces por Álvarez.

Es curioso, en efecto, advertir que este autor, fundado en las opiniones del citado Heineccius, considera que la necesidad de una tradición como modo de adquirir el dominio de las cosas sea una sutileza del derecho civil, vale decir, del romano, a la que el derecho natural no atiende, de modo que, según este: “[...] cualquier, verdadero señor con derecho expedito, que tiene ánimo o voluntad de enajenar y la declara expresamente o por señales destinadas al efecto, transfiere el dominio válidamente, aunque no intervenga tradición de la cosa" ${ }^{23}$. Álvarez escribió estas palabras cuando habían transcurrido más de veinte años desde que el Code Civil tenía acogida la vieja opinión iusnaturalista y abolido la tradición como modo de adquirir, según veremos luego; pero ya se ve que su fuente no fue dicho código sino Heineccius.

\section{EL REEMPLAZO DE LA TRADICIÓN POR EL CONSENTIMIENTO EN EL PENSAMIENTO IUSNATURALISTA Y EN EL "CODE CIVIL"}

1. La escuela del derecho natural consideró a la tradición -ya lo adelantamos- no más que como una exigencia del derecho civil, vale decir, del derecho romano, que no se aviene con el derecho natural en cuanto, según este, basta el mero consentimiento del transferente y del adquirente para que el último adquiera el dominio. En el interior de dicha escuela, Grotius aparece como el iniciador de la nueva perspectiva; pero, en realidad,

21 Esta cédula de Carlos V posteriormente fue recogida en Rec. Ind. II, 1, 2.

22 Álvarez (1818/1827) lib. II, tít. 1º, 2a parte, \$ vii, II, pp. 66-71.

23 Álvarez (1818/1827) lib. II, tít 1o, 2a parte (tomo II, p. 69-70). Álvarez cita Heineccius, Iohannes, Elementa iuris naturae et gentium, lib. I, cap. $10^{\circ}, \$ 275$. Sobre el particular, ya antes, véase: GUZMÁN BRITO (1997) I, pp. 481-498 y en especial 494. 
antes que él, ya Francisco de Vitoria la había hecho notar ${ }^{24}$. Fuera como haya sido, el hecho es que la prescindencia de la tradición por el derecho natural se hizo doctrina común a partir de Grotius ${ }^{25}$ y se la observa en Pufendorf ${ }^{26}$, Thomasius ${ }^{27}$ y Wolf ${ }^{28}$, por citar a los más destacados ${ }^{29}$.

Ocurría que en la práctica francesa, desde luego moderna, pero seguramente anterior, que la declaración de haber tenido lugar el desposeimiento del vendedor y el posesionamiento del comprador, vale decir, el traspaso posesorio de la cosa vendida por el vendedor al comprador, se había convertido en una cláusula de estilo rutinaria en los contratos de compraventa redactados por los notarios; se hablaba entonces "desaisine-saisine" que, como se ve, podía ser puramente documental sin correspondencia real. También se recurría al constituto posesorio ${ }^{30}$. En todo caso, como parece, se trataba de omitir la tradición efectiva y de convertirla en puramente documental. Debe advertirse que esta práctica no implicó, en realidad, abolir la tradición ${ }^{31}$, mas solo eludirla y, como siempre acaece, toda elución paradójicamente contiene un homenaje a la existencia de lo eludido. Por consiguiente, dicha práctica no fue la razón de que el Code Civil haya adoptado la solución que pasamos a referir, sino solo la creadora de una atmósfera de prescindencia de la tradición real, que permitió recoger las ideas iusnaturalistas y adoptarla sin tropiezos.

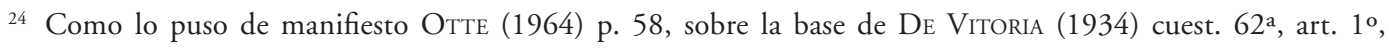
núm. 30, p. 84. Vitoria se pregunta si para transferir el dominio de una cosa por derecho natural sea suficiente un mero acto interior de querer transferirlo y responde que no por varias razones; una de ellas es que para la transferencia se requiere una tradición, como lo sostiene la universalidad de los juristas; y entonces afirma: "Sed quidquid sit, nibilominus in iure naturali non requireretur traditio actualis, sed sufficeret acceptatio per voluntatem formalem vel interpretativam, ita quod nibil refert an sit actus exterior vel interior" ("Pero como quiera que sea, no es menos cierto que por derecho natural no se requiere una tradición actual, sino que es suficiente la aceptación merced a una voluntad formal o presumida, así que nada importa que se trate de un acto interior o exterior”.) Cfr. Birocchi (1991) pp. 156-159.

25 Grotius (1939), De iure belli ac pacis, lib. II, cap. 6º párr. 1, p. 261; ibid., lib. II, cap. 8, párr. 24, ed. cit., p. 308; y lib. II, cap. 12º párr. 16, ed. cit., p. 349. La afirmación de Grotius está inserta en un contexto en el que discute si la transferencia del dominio puede ser obra de un acto interno, como en Vitoria.

26 Pufendorf (1759/1967), lib. IV, cap. 9o, \$\$ 5, 6 y 8, I, pp. 596-597 y 599-601. Pufendorf cita a Grotius y también inserta la cuestión en el tema de la potencia de un acto interno de voluntad para transferir el dominio.

27 Thomasius (1720), lib. II, cap. 101, párr. 161, p. 203.

28 Wolf, Christian (1750/1969), \$\$ 314, 316-317 y 320, pp. 162-163.

29 Para la doctrina iusnaturalista sobre el mero consenso como modo de transferir el dominio: GORDON (1970) pp. 172-178; SCHRAGE (2003) pp. 944-946.

30 Sobre la materia: Levy, Jean-Philippe - Castaldo (2002) núm. 396 (“Le déclin de la tradition”), pp. 577 578. Véase también: Petronio (1991) pp. 169-186.

31 De hecho, Pothier (1861) IV, p. 186-187, discute el punto, como se anuncia a traves de la rúbrica, con cita expresa a "Grotius et plusieurs autres qui ont écrit sur le Droit naturel"; pero luego de exponer las doctrinas iusnaturalista sobre la materia, Pothier declara: "Quoi qu' il soit de cette question traitée selon le pur droit naturel, qui nous abandonnons à la dispute de lécole, le principe de Droit romain que 'le domaine de propriété d’ une chose ne peut passer d’une personne à une autre que par la tradition réelle ou feinte de la chose', étant un principe reçu dans la jurisprudence, comme en conviennent ceux qui sont de lopinion contraire, nous devons y tenir". En el avanzado siglo XVIII, pues, Pothier reafirma la doctrina romana, combate las ideas iusnaturalista y ni siquiera menciona la práctica de sustituir la tradición por una simple declaración. 
2. El artículo 711 del Code Civil ${ }^{32}$, el primero de su libro III: Des différentes manières dont on acquiert la propriété expresó que esta última se adquiere por sucesión, por donación entre vivos y por "l'effet des obligations". El inciso $1^{\circ}$ del artículo 1138 del mismo cuerpo legal vigorizó la idea al disponer: "L'obligation de livrer la chose est parfaite par le seul consentement des parties contractantes"; y el inciso 2a explicó: "Elle [la obligación de entregar la cosa] rend le crèancier propriétaire et met la chose à ses risques dès l'instant où elle a dî être livrée, encore que la tradition n'en ait point été faite [...]”. El artículo 1583 aplica la doctrina de las disposiciones antes citadas al contrato de compraventa, cuando dice que esta "est parfaite entre les parties, et la propriété est acquise de droit à l'acheteur à l'égard du vendeur, dès qu'on est convenu de la chose et du prix, quoique la chose n'ait pas encore été livrée ni le prix payé"33. El artículo 938 sobrepone la misma idea a las donaciones ${ }^{34}$. De hecho, sin embargo, la doctrina de la adquisición por contrato traslaticio vale solo para los inmuebles. Cuando la obligación de dar o entregar recae sobre un mueble, en cambio, la posesión (generalmente derivada de la entrega) cobra relevancia. El principio general aparece formulado en el artículo 2279: "En fait de meuble, la possession vait titre", en donde "titre" significa, en realidad, "modo de adquirir" 35 .

Este conjunto de normas son manifestación de un nuevo diseño: en el caso de los inmuebles, la tradición queda reducida solo a un modo de adquirir la posesión; el dominio, en cambio, se adquiere por el contrato traslaticio, como la compraventa, la permuta o la donación, o, como dice el artículo 1138 inciso $2^{\circ}$, se adquiere de derecho por la obligación perfeccionada de entregar la cosa. No es el caso detenernos en las dificultades dogmáticas creadas por el nuevo sistema ni en las críticas que se le han dirigido.

3. En Europa ${ }^{36}$, la nueva concepción fue introducida en los países en que el Code Civil fue puesto en vigencia como todavía es el caso de Bélgica. También fue acogida por algunos códigos que no eran el francés pero que fueron redactados bajo su influjo intenso, como el de Piamonte-Cerdeña de $1837^{37}$ y del de Italia de $1865^{38}$ que en el punto fue seguido por su sucesor de 1942. El código de Portugal de 1865 fue un caso especial,

\footnotetext{
32 Code Civil des Français (1804).

33 La obligación de entregar la cosa vendida es tomada como modelo para todo acto o contrato que contenga la entrega de una cosa inmueble. Al respecto, dice el artículo 1140: "Les effets de lobligation de donner ou de livrer un immeuble sont réglés au titre de la Vente et au titre des Privilèges et Hypothèques".

34 Code Civil, artículo 938: "La donation dûment acceptées sera parfaite par le seul consentement des parties et la propriété des objets donnés sera transférée au donataire. Sans qu'il soit besoin dautre tradition”.

35 Esto explica que cuando se contrae la obligación de dar o entregar un mueble sucesivamente a dos personas, se prefiera al que esté en su posesión (de buena fe), aunque su título traslaticio sea posterior al del otro. Esta preferencia acordada la posesión implica, en definitiva, dar relevancia a la tradición.

36 Un panorama acerca de la postura asumida por los códigos europeos del siglo XIX frente a la doctrina del Code Civil (y sobre esta misma) se ve en: Schrage, Eltjo (2003), pp. 946-955. Véase también: Danos, Frédéric (2013), pp. 659-687.

37 Code Civil du Royaume de Sardaigne (1844), artículo 680: "La propriété des biens s'acquiert et se transmet par succession, par donation entre-vifs et par l effet des autres obligations”.

38 Codice Civile del regno d' Italia (1865), artículo 710 inciso 20: "La proprietà e gli altri diritti sulle cose si acquistano e si trasmettono per successione, per donazione e per effetto di convenzioni".
} 
porque no habiendo tenido como modelo al código de Francia, que meramente usó como una fuente más, en esta última calidad hubo de adoptar el nuevo dogma ${ }^{39}$. Pero este no cobró fuerza en códigos como el de Holanda ${ }^{40}$ de 1838, ni de España de $1889^{41}$. Tampoco había sido acogido en el código de Austria de $1811^{42}$ ni lo sería en el de Alemania de $1897 / 1900^{43}$, los cuales, por lo demás, se sustrajeron al influjo general del francés porque siguieron líneas diversas y propias de desarrollo.

\section{EL DESTINO DE LA TRADICIÓN EN LAS CODIFICACIONES MODERNAS DE LA AMÉRICA ESPAÑOLA}

En los códigos civiles que poco a poco empezaron a ser promulgados a lo largo del siglo XIX en los países americanos que otrora habían hecho parte de la monarquía española, el modo de adquirir tradición era un elemento constitutivo de su herencia jurídica, así que todo hacía presumir que iría a ser conservada en los nuevos cuerpos legales con que se sustituyera a la legislación castellano-indiana. De hecho tal fue lo acaecido en muchos casos, pero hubo excepciones,

\footnotetext{
39 Código Civil Portugués (1939), artículo 715: "Nas alienaçôes de coisas certas e determinadas, a transferência da propiedade opera-se entre os contraentes, por meo efeito do contrato, sem dependência de tradição ou de posse, quer material, quer simbólica, salvo havendo acordo das partes em contrario".

40 Siento no haber podido disponer de una edición original de este cuerpo legal; en sustitución he visto su traducción al castellano en: Romero y Girón, Víctor (director) (1890), VI: Instituciones y códigos de Holanda, Código Civil de Holanda, artículo 639: "La propiedad se adquiere por ocupación, por accesión, por prescripción, por sucesión legal o testamentaria y por tradición en virtud de un título que otorga quien transfiere el dominio"; a la tradición van reservados sus artículos 667 a 671.

${ }^{41}$ Código Civil de España, artículo 609 inciso 20: "La propiedad y los demás derechos sobre los bienes se adquieren y transmiten por la ley, por donación, por sucesión testamentarias e intestada y por consecuencia de ciertos contratos mediante tradición".

${ }^{42}$ Allgemeines bürgerliches Gesetzbuch für die gesammten deutschen Erbländer der österreichischen Monarchie (1811), $\$ 423:$ "Sachen, die schon einen Eigenthïmer haben, werden mittelbar erworben, indem sie auf eine rechtliche Art von dem Eigenthümer auf einen Andern übergehen". \$425: "Der bloße Titel gibt noch kein Eigenthum. Das Eigenthum und alle dingliche Rechte überhaupt können, außer den in dem Gesetze bcstimmten Fallen, nur durch die rechtliche Uebergabe und Uebernahme erworben werden" ( $\$$ 423: "Las cosas que ya tienen un dueño son adquiridas inmediatamente en el instante en que son entregadas por el dueño a otro de una manera ajustada a derecho". $\$ 423$ : "El solo título no da la propiedad. La propiedad y todos los derechos reales, fuera de los casos determinados por la ley, solo son adquiridos por una entrega y una recepción ajustadas a derecho"). Véase: Petronio, U., "Vendita", cit. en la nt., pp. 187-193.

43 Para la transferencia de un predio, el $\$ 873$ del Bürgerliches Gesetzbuch (1908) exige acuerdo de las partes en orden a transferir e inscripción del acto en el Registro de Bienes Raíces. Añade en su $\$$ 929: “Zur Übertragung des Eigentums an einer beweglichen Sache ist erforderlich, daß der Eigentümer die Sache dem Erwerber übergibt und beide darüber einig sind, daß das Eigentum übergehen soll [...]" ("Para la transferencia de la propiedad de una cosa mueble es necesario que el dueño entregue la cosa al adquirente y que ambos estén de acuerdo en que la propiedad debe transitar [...].") Con todo, el BGB. adoptó la doctrina de Savigny, que en cuanto al título traslaticio de la tradición se contentaba con uno abstracto, consistente en el acuerdo de transferir, y no exigía un título concreto y típico, como la compraventa, la donación, la permuta, que queda fuera de la transferencia y no se ve afectada por sus eventuales vicios.
} 
En la América española ${ }^{44}$, pues, el destino de la tradición fue doble ${ }^{45}$ :

1. En los países que adoptaron el Code Civil, o que lo adaptaron o que se basaron en otro influido por él, en todos los casos se hubo de introducir el principio de la adquisición por contrato o por efecto de la obligación emanada de él, que conducía a despojar de su efecto dominical a la tradición. Todavía es así en el caso de recepción total ocurrida en la República Dominicana que adoptó el Code Civil en $1845^{46}$ y por supuesto en Haití -aunque mencionándola excedamos el ámbito de la América española- que había hecho lo propio en $1825^{47}$. Lo semejante acaeció en aquellos países que no adoptaron completamente el Code Civil, sino que elaboraron un cuerpo legal propio en el cual aquel venía adaptado: es el caso de Bolivia en $1830^{48}$, cuyo código de ese año a su vez fue adoptado íntegramente por Costa Rica en $1841^{49}$, el cual fue sustituido en 1888 por otro, en que fueron recogidas las reglas francesas, como veremos. En fin, acaeció el mismo fenómeno en un caso de recepción indirecta del código francés, como fue el de Venezuela, que en 1873 puso en vigencia un cuerpo legal que seguía muy de cerca el Codice Civile italiano de $1865^{50}$, que, como quedó dicho, había recogido el sistema francés. Otro tanto debe decirse del Código Civil de

\footnotetext{
44 En lo sucesivo se cita frecuentemente: Guzmán Brito, Alejandro (2000), y Guzmán Brito, Alejandro (2006), que es una suerte de segunda edición con anexos, de la obra primeramente citada.

45 Una tesis doctoral de 1981, dirigida por el profesor de la Universidad de Berna, Dr. Eugen Bucher, fue presentada por Andreas Röthlisberger (1982) bajo el título de Traditionsprinzip und Konsensprinzip bei der Mobiliarïbereignung. Eine vergleichende Untersuchung zu der iberischen und lateinamerikanischen Kodifikationen ["El principio de la tradición y el principio del consenso en la transferencia mobiliaria. Una investigación comparatística de las codificaciones ibéricas y latinoamericanas"], en que se contrastan los códigos del área en función de haber acogido la tradición como modo de adquirir o de haberla sustituido por el contrato, que no deja de ser útil para conocer la distribución de ambos principios en la América española.

46 Sobre el particular: GuZMÁn Brito (2000) $\$ 28$; y GUZMÁn Brito (2006) $\$ 17$.

47 GUZMÁn Brito (2000) $\$ 27$; y GUZMÁn Brito (2006) $\$ 16$.

48 Código Civil Boliviano (1885), artículo 437: "La propiedad de los bienes se adquiere y trasmite por sucesión, por donación entre vivos o testamentaria; y por el efecto de los contratos". El código de 1830 perdió vigencia entre el 18 de noviembre de 1845 y el 11 de noviembre de 1846, y entonces fue sustituido por otro [Código Civil boliviano (1845)], que en la materia que aquí interesa mantuvo el principio de la adquisición del dominio por contrato. Su artículo 653, en efecto, dijo: "Se adquiere y se trasmite la propiedad de los bienes adquiridos originariamente, por sucesión, por donación, por prescripción y por medio de los contratos”. Este cuerpo legal fue sucedido por el de 1830, que quedó, pues, restablecido y rigió hasta 1975. El nuevo código boliviano de 1975, entre cuyas fuentes principales se cuenta el italiano de 1942, mantuvo (igual que este) el principio ya adoptado en 1830, de permitir la adquisición por contrato; así, su artículo 110 dice: "La propiedad se adquiere por ocupación, por accesión, por usucapión, por efecto de los contratos, por sucesión mortis causa, por la posesión de buena fe y por lo otros modos establecidos por la ley" (cfr. el artículo 922 CCIt.). Sobre la codificación en Bolivia: GuZMán Brito (2000), $\$ 30,33$ y 68; y GuZMÁn Brito (2006) $\$ 19$, 22 y 57.

49 Guzmán Brito (2000) $\$ 32$; y GuZmán Brito (2006) $\$ 21$.

50 Código Civil sancionado por el general Guzmán Blanco (1973/1973), artículo 668: "La propiedad y demás derechos se adquieren y trasmiten por sucesión, por donación y por efecto de los contratos./ Pueden también adquirirse por medio de la prescripción". La norma es igual a la del artículo 710 del código italiano de 1865 (salvo en cuanto este dice: "per effeto di convenzioni"). Sobre el código de 1873 y su lugar en la historia de la codificación en Venezuela, véase: GuZMÁn Brito (2000) $\$ \$ 34$ y 54; y GuZMÁn Brito (2006), $\$ \$ 23$ y 43. Este cuerpo legal aún se encuentra en vigencia, pese a haber sido objeto de muchas intervenciones: el artículo 668 original ahora lleva el número 796.
} 
México de 1870, cuyo artículo 1552 tradujo a la letra el artículo 715 del código de Portugal de $1865^{51}$, que a su turno también se había acomodado al criterio del Code Civil.

2. El resto de los países, en cambio, se mantuvo fiel al dogma romano-castellanoindiano de la tradición. Así acaeció por la primera vez en el Código Civil del Perú promulgado en 1852, en el cual, empero, la tradición viene denominada "enajenación" 52 , con reserva de aquel término para designar el requisito consistente en la entrega ${ }^{53}$. Pero este cuerpo legal destinó una muy parca reglamentación a la enajenación; la cual, por otro lado, pasó, con el íntegro código peruano y adiciones tomadas de otros, a Guatemala en $1877^{54}$. La tradición, en cambio, fue recibida con toda su disciplina romanística, ampliamente expuesta en el Código Civil de Chile de $1855^{55}$. Esa disciplina fue íntegramente trasladada a los países que adoptaron el código chileno de manera persistente, vale decir, Ecuador desde 1858, Colombia sucesivamente en sus estados componentes cuando presentaba forma federal, desde 1858, y en todo el Estado en 1887, después de haber adoptado la forma unitaria; El Salvador en 1859; y Honduras, primero en $1880^{56}$ y después hasta hoy en $1906^{57}$. El régimen descrito en el código chileno tuvo alguna influencia en el código del Uruguay promulgado en $1868^{58}$. También adoptó la tradición como modo de adquirir el dominio el

51 El Código Civil del Distrito Federal y Territorio de la Baja California (1872), artículo 1552 dice: "En las enajenaciones de cosas cierras y determinadas, la traslación de la propiedad se verifica entre los contratantes por mero efecto del contrato, sin dependencia de tradición, ya sea natural, ya simbólica, salvo convenio en contrario”. Cfr. con el artículo 715 del código de Portugal, cuyo texto se reproduce en la nota. Véanse: GUZMÁN BRITO (2000), \$48; y GuZMán BRITO (2006), \$37.

52 Código Civil del Perú (1870), artículo 571: "Por la enajenación se transfiere a otro el dominio de una cosa, o a título gratuito, como en la donación, o a título oneroso, como en la venta y la permuta". Sobre este cuerpo legal: GuZmán Brito (2000), \$35; y GuZMán Brito (2006), \$24.

53 Código Civil del Perú (1870), artículo 574: "La enajenación se completa por la tradición, que es la entrega que se hace de una cosa poniéndola a disposición del nuevo dueño".

54 Artículos 690 a 695, idénticos a los artículos 571 a 577 del código peruano de 1852. Sobre el código guatemalteco de 1877: GuZMÁn Brito (2000) \$37; y GuZMÁn Brito (2006) \$ 26.

55 Código Civil de Chile (1856), artículo 588 inciso $1^{\circ}$ : "Los modos de adquirir el dominio son la ocupación, la accesión, la tradición, la sucesión por causa de muerte y la prescripción”. De la tradición trata en el título 60 del libro II a lo largo de treinta artículos (670 a 699). El artículo 670 la define así: "La tradición es un modo de adquirir el dominio de las cosas y consiste en la entrega que el dueño hace de ellas a otro, habiendo por una parte la facultad e intención de transferir el dominio, y por la otra de capacidad e intención de adquirirlo./ Lo que se dice del dominio se extiende a todos los otros derechos reales". El artículo 675 inciso $1^{\circ}$ redondea la precedente definición: "Para que valga la tradición se requiere un título traslaticio de dominio, como el de venta, permuta, donación, etc.”. Sobre este cuerpo legal, véanse: GuZmán Brito (2000) \$38; y GuZMÁn BRito (2006) \$27. La formación del título sobre la tradición del libro II del código chileno, véase: BARRIENTOS (2003) pp. 11-108.

56 El código de 1880 era un cuerpo que se basaba muy de cerca en el chileno de 1855 . Sobre él, véanse: GuzMÁN BRITO (2000) \$ 44; y GUZMÁN BRITO (2006) \33.

57 El título 60 del libro II del código vigente desde 1906 en Honduras se rubrica De la tradición y contiene casi toda la reglamentación del título homónimo del código de Chile; hemos tenido a la vista: República de Honduras, Código Civil (1906).

58 Código Civil de la República Oriental del Uruguay (1893) artículo 680: "Los modos de adquirir el dominio son la ocupación, la accesión, la tradición, la sucesión por causa de muerte y la prescripción”, el cual, como se ve, es copia fiel del artículo 588 inciso $1^{\circ}$ CCCh. Pero el código uruguayo añade este inciso $2^{\circ}$ : "Los títulos de adquirir solo producen efecto personal, esto es, derecho a la cosa, ad rem", con lo cual se hace eco de la doctrina del título y modo entendida como general, aunque de hecho ella solo vale para algunos títulos de la tradición, como la com- 
código de la Argentina promulgado en $1869^{59}$; y el régimen establecido en él pasó con todo el código argentino al Paraguay, cuando este fue promulgado ahí en $1876^{60}$.

Cuba y Puerto Rico también permanecieron fieles al modo de adquirir denominado tradición, porque en 1889 les fue extendida la vigencia del Código Civil de España que había sido promulgado en aquel mismo año, y de cuya Corona a la sazón aún hacían parte. El código español de 1889 hubo de conservar la tradición como modo de adquirir, aunque lo hizo de manera ecléctica ${ }^{61}$. En $\mathrm{Cuba}^{62}$ él fue sustituido por uno nuevo que se promulgó en 1987, el cual, de manera poco clara, parece que mantuvo la idea de necesitarse tradición para la transferencia de cosas entre vivos ${ }^{63}$. En Puerto Rico, el código promulgado en 1889 para esa isla ha sufrido innumerables modificaciones posteriores, pero todavía su artículo 549 inciso $2^{\circ}$ conserva el texto del artículo 609 inciso $2^{\circ}$ español ${ }^{64}$.

praventa, la permuta o la donación. Este código reserva a la tradición el título $3^{\circ}$ del libro III, y en él a veces se observa la presencia de la normativa chilena. Véanse: GUZMÁn BRITO (2000) $\$ 51$; y GUZMÁn BRITO (2006) $\$ 40$.

59 Código Civil de la República Argentina (1870), artículo 2524: "El dominio se adquiere: [...]. 40 Por la tradición.". De donde que el artículo 577 exprese: "Antes de la tradición de la cosa el acreedor no adquiere sobre ella ningún derecho real”. Cfr. con el artículo 3265. La regulación, más bien parca pero esencial, comparece en el capítulo $4^{\circ}$ del título $5^{\circ}$ del libro III bajo la rúbrica de De la tradición traslativa del dominio. Su artículo 2601 la define así: "Para que la tradición traslativa de la posesión haga adquirir el dominio de la cosa que se entrega, debe ser hecha por el propietario que tenga capacidad para enajenar, y el que la reciba ser capa adquirir"; el artículo 2603 añade: "La tradición debe ser por título suficiente para transferir el dominio"; y el artículo 2603 complementa: "Los únicos derechos que pueden transmitirse por la tradición, son los que son propios del que la hace". Véase: LeVAGGi (2003) II, pp. 977-978. Sobre la codificación en Argentina: GuZmán Brito (2000) $\$$ 49; y GUZMÁn BRITO (2006) $\$ 38$.

60 Sobre la codificación en Paraguay: GuZmán Brito (2000) $\$ \$ 50$ y 70; y GUZMÁn Brito (2006) $\$ \$ 39$ y 59. Pero en el nuevo código paraguayo de 1987 se innovó radicalmente en esta materia. Su artículo 1966 letra a) declaró que la propiedad de los inmuebles se adquiere por contrato y el tema fue regulado en los artículos 1968 a 1973. Por su lado, con respecto a la propiedad de los muebles, el código adoptó un régimen muy poco claro: esa propiedad se adquiere merced a una tradición abstracta, vale decir, la entrega del bien por el dueño a un tercero con acuerdo mutuo para transferir la propiedad (artículo 2062), o bien por contrato (artículo 2061); pero cuando el propietario tiene la posesión, la tradición se efectúa "por el convenio de constituir al adquirente en poseedor mediato". En este confuso sistema intervienen la tradición romana, el sistema francés y la tradición germánica con título abstracto.

${ }^{61}$ Código Civil de España (1889), artículo 609 inciso 2o: "La propiedad y los demás derechos sobre los bienes se adquieren y transmiten por la ley, por donación, por sucesión testamentarias e intestada y por consecuencia de ciertos contratos mediante tradición”. El artículo 548 del Proyecto de Código Civil de España de 1852, debido principalmente a GARCíA GoYENA (1852) II, p. 3, había dicho: "La propiedad se adquiere por herencia, contrato y prescripción"; y el artículo 981 declarado en consecuencia: "La entrega de la cosa no es necesaria para la traslación de la propiedad [...]./ La propiedad pasa al acreedor y la cosa está a su riesgo desde que el deudor quede obligado a su entrega [...]", en el entendido de que el deudor queda obligado a entregar la cosa desde que se perfecciona el contrato (de compraventa, por ejemplo). Este proyecto tuvo su influencia en el texto promulgado en 1889 y bien puede ser que la ecléctica manera de definir un modo consistente en la "consecuencia de ciertos contratos mediante tradición" se haya debido al deseo de no apartarse demasiado de sus ideas, no obstante que de hecho eran repudiadas cuando se exigió la tradición. Sobre la codificación en España: GuZmán BRITO (2000) $\$ \$ 46$ y 55; y GUZMÁN BRITO (2006) $\$ \$ 35$ y 44.

62 Véanse: GuZMán Brito (2000) $\$ \$ 57$ y 71; y GuZMÁn BRITO (2006) $\$ \$ 46$ y 60.

${ }^{63}$ Código Civil [de Cuba] (1989), Ley No 59, artículo 178: "La propiedad y demás derechos sobre bienes se adquieren y transmiten por la ley, los acontecimientos naturales, los actos jurídicos, la accesión y la usucapión. La transmisión se consuma mediante la entrega o posesión".

${ }^{64}$ Véase la nota. GuZmán Brito (2000) $\$ 56$; y GuZMÁn Brito (2006) $\$ 45$. 
3. Examinemos, en fin, dos cuerpos legales que ofrecen rasgos especiales en la materia que nos ocupa.

a) El primero es el código de Costa Rica de 1888, que reemplazó al de 1842 y aun rige. Él, como su antecesor, adoptó las reglas que la doctrina francesa hubo de establecer para imponer armonía al régimen casuístico del Code Civil: el dominio de muebles e inmuebles se transfiere por el solo hecho del contrato traslaticio, pero solo entre las partes contratantes $^{65}$, lo cual parece una generalización de la norma que el artículo 1583 del código francés formula para la compraventa; respecto de terceros, el dominio de los muebles se adquiere merced a la tradición ejecutada a virtud de un título hábilib; y el de los inmuebles por la inscripción del título en el Registro de Propiedad ${ }^{67}$.

b) En el código nicaragüense de $1904^{68}$ no existe alguna disposición general en que se diga que la tradición sea modo de adquirir, ni la hay en la cual se exprese que la propiedad se adquiere desde el momento en que un contrato traslaticio quede perfecto o que se adquiere por contrato sin necesidad de tradición. Sin embargo, hay normas singulares que suponen la adquisición por contrato, como, entre otras, el artículo 2530, que define la compraventa como un contrato por el cual una parte transfiere a la otra el dominio de una cosa; $y$, en contra, las hay que suponen la tradición como modo de adquirir, como la del artículo 2675 que, en el caso de doble venta, concede el dominio al primero que haya entrado en posesión de la cosa y no al primero que compró. Esta contradicción de principios es muy frecuente en el código nicaragüense, a formar el cual concurrieron numerosas fuentes fundadas en premisas diversas, pero que fueron usadas sin discernimiento ni unidad de criterios por los codificadores.

\section{BIBLIOGRAFÍA}

Allgemeines bürgerliches Gesetzbuch für die gesammten deutschen Erbländer der österreichischen Monarchie (1811), Wien, Aus der k. k. Hof- und Staats-Druckerey.

Álvarez, José María (1818/1827): Instituciones de derecho real de Castilla e Indias (2a edición, Nueva York, Lanuza, Mendìa y C., II).

Barrientos Grandón, Javier (2003): "De la "tradición” y su definición en el "Código Civil" chileno", Revista Chilena de Derecho Privado "Fernando Fueyo Laneri”, No. 1, pp. 11-108.

Bartolo a Sassoferrato (1526/1996), Super prima in Codicis, Venetiis, B. de Tortis (reimpresión Roma, Il Cigno Galileo Galilei, VII).

BESTA, Enrico (1964): I diritti sulle cose nella storia del diritto italiano (Milano, Giuffrè).

65 República de Costa Rica, Código Civil (1887), artículo 480: "La propiedad de muebles e inmuebles se trasmite con relación a las partes contratantes, por el solo hecho del convenio que tenga por objeto transmitirla, independientemente de su inscripción en el Registro y de la tradición”.

66 República de Costa Rica, Código Civil (1887), artículo 481: "La propiedad de los muebles se adquiere eficazmente respecto de terceros, por la tradición hecha a virtud de un título hábil [...]”. Véanse: GUZMÁN BRITO (2000) \$ 52; y GuZMán BRITo (2006) \$ 41.

67 República de Costa Rica, Código Civil (1887), artículo 459 № 1.

68 Sobre él: GuZMÁn Brito (2000), $\$ 53$; y GuZMÁn Brito (2006), $\$ 42$. 
Birocchi, Italo (1991): "Vendita e trasferimento della proprietà nel diritto comune", en Vacca, L. (edit.), Vendita e trasferimento della proprietà nella prospettiva storico-comparatistica (Milano, Giuffrè).

Bürgerliches Gesetzbuch (1908): edición de Wolf, B., Das Bürgerliche Gesetzbuch unter Berücksichtigung der gesamten Rechtsprechung der oberen Gerichte des Deutschen Reichs. Hand-Kommentar, Halle a. S., Buchhandlung des Waisenhauses.

Busi, Emilio (1937): La formazione dei dogmi di diritto privato nel diritto comune (diritti reali e diritti di obbligazione), (Padova, Cedam).

CoIng, Helmut (1996), Derecho privado europeo, traducción castellana (Madrid, Fundación Cultural del Notariado, s.d., I).

Danos, Frédéric (2013): "Étude sur les différents systèmes de transfert de la propriété: les exemples du Code prussien de 1794, du Code civil autrichien de 1811 et du Code civil espagnol de 1889", en Revue Historique de Droit Français et Étranger, fasc. 4.

De Vitoria, Francisco (1934): De iustitia, edición preparada por el R. P. Vicente Beltrán de Heredia, O.P. (Madrid, Publicaciones de la Asociación Francisco de Vitoria).

Degli Ubaldis, Baldus (1599/2004), In primum, secundum, tertium Codicis libros commentaria, Venetiis (reimpresión Golbach, Keip, V).

García Goyena, Florencio (1852): Concordancias, motivos y comentarios del Código Civil español (Madrid, Imprenta de la Sociedad Tipográfico - Editorial, II).

Gordon, William M. (1970): Studies in the Transfer of Property by "traditio" (Aberdeen, University Press).

Grotius, Hugo (1839/1993): De iure belli ac pacis, edición De Kanter-van Hettinga Tromp, B. J. A., Lugduni Batavorum, Brill (reimpresión Aalen, Scientia).

GuZMÁn Brito, Alejandro (1997): "La literatura de derecho natural racionalista y la literatura de derecho indiano con especial referencia a las 'Instituciones' de José María Álvarez", en XI Congreso del Instituto Internacional de Historia del Derecho Indiano (Buenos Aires, Instituto de Investigaciones de Historia del Derecho, I).

GuZmán Brito, Alejandro (2000): La codificación civil en Iberoamérica. Siglos XIX y XX (Santiago de Chile, Editorial Jurídica de Chile).

GuZMÁn Brito, Alejandro (2006): Historia de la codificación civil en Iberoamérica, Cizur Menor, Pamplona, Navarra, Thomson - Aranzadi.

GuZmán Brito, Alejandro (2013): Derecho privado romano (Santiago de Chile, LegalPublishing - Thomson Reuters, I).

Hoffmann, Franz (1873): Das Dogma vom "titulus" und “modus acquirendi" (Wien, Verlag der B. J. Manz'schen Buchhandlung).

Jordán de Asso y del Río, Ignacio y Rodríguez, Miguel (1771/1792): Instituciones del derecho civil de Castilla (Madrid, Imprenta de Ramón Ruiz: reimpresión facsimilar Valladolid, Lex Nova, s.d.).

Lalinde Abadía, Jesús (1978): Iniciación histórica al derecho español (Barcelona y otras, Ariel, segunda edición).

Las siete Partida del sabio rey don Alonso el Nono nuevamente glosadas por el licenciado Gregorio López del Consejo Real de Indias de Su Majestad (1555) (Salamanca, A. de Portonaris, reimpresión Madrid, Imprenta Nacional del Boletín Oficial del Estado, s.d.). 
Levaggi, Abelardo (1982): Historia del derecho de las obligaciones, contratos y cosas (Buenos Aires, Editorial Perrot, s.d).

Levaggi, Abelardo (1987): Manual de historia del derecho argentino (castellano, indiano/nacional) (Buenos Aires, Depalma,, II: Judicial, civil, penal).

Levaggi, Abelardo (2003): "Pervivencia del derecho castellano-indiano en el Código Civil argentino y en otras obras del codificador", en Luis González Vales (coordinador), XIII Congreso del Instituto Internacional de Historia del Derecho Indiano, San Juan, 21 al 25 de mayo de 2000. Estudios (San Juan, Asamblea Legislativa de Puerto Rico, II).

Levy, Jean-Philippe y Castaldo, André (2002) Histoire de droit civil (Paris, Dalloz).

Отте, Gerhard (1964): Das Privatrecht bei Francisco de Vitoria (Köln - Graz, Böhlau).

Petronio, Ugo (1991): "Vendita, transferimento della proprietà e vendita di cosa altrui nella formazione del 'Code Civil' e dell'AAllgemeines Bürgerliches Gesetzbuch'”, en Vacca, L. (editora), Vendita e trasferimento della proprietà nella prospettiva storico-comparatistica (Milano, Giuffrè).

Pothier, Robert-Joseph (1861): Traité du droit de domaine de propriété, en Euvres de Pothier (edición de J.-J. Bugnet, Paris, H. Plon - Cosse et Marchal, IV).

PufENDORF, Samuel (1759/1967): De jure naturae et gentium (Francofurti - Lipsiae, Ex Officin Knochio-Eslingeriana, reimpresión Frankfurt am Main, Minerva).

Romeo, Stefania (2010): L'appartenenza e l alienazione in Diritto romano. Tra giurisprudenza e prassi (Milano, Giuffrè).

Romero y Girón, Víctor (director) (1890): Colección de las instituciones políticas y jurídicas de los pueblos modernos, Madrid, José Góngora, VI: Instituciones y códigos de Holanda, Código Civil de Holanda.

Röthlisberger, Andreas (1982): Traditionsprinzip und Konsensprinzip bei der Mobiliarübereignung. Eine vergleichende Untersuchung zu der iberischen und lateinamerikanischen Kodifikationen (Zürich, Schulthess Polygraphischer Verlag, s.d.).

Schrage, Eltjo (2003): “'Traditionibus et usucapionibus, non nudis pactis dominia rerum transferuntur'. Die Wahl zwischen dem Konsens- und dem Traditionprinzip in der Geschichte", en Ascheri, M. y otros (editores), "Ins Wasser geworfen und Ozeane durchquert". Festschrift für Knut Wolfgang Nörr (Köln y otras, Böhlau).

TAPIA, Eugenio (1828): Febrero novísimo o librería de jueces, abogados y escribanos, lib. II, tít. $1^{\circ}$, cap. $4^{\circ}$, núm. 10, Valencia, Ildefonso Mompié, I.

Thomasius, Christian (1720), Institutiones iurisprudentiae divinae, Halae Magdeburgicae, Sumpt. ex typis viduae Chr. Salfeld.

VACCA, Letizia (2013): "Emptio venditio" e "iusta causa traditionis" (a proposito di alcuni libri recenti), en Studia et Documenta Historiae et Iuris, 79.

Wolf, Christian (1750/1969), Institutiones iuris naturae et gentium in quibus ex ipsa hominis natura continuio nexu omnes obligationes et iura omnia deducuntur, Halae Magdeburgicae, in Officina Rengeriana,, reimpresión en Wolf, Christian, Gesammelte Werke, Herausgegeben und Bearbeitet von L. École (y otros), II. Abteilung: Lateinische Schriften, Band 26: Institutiones iuris naturae et gentium, Herausgegeben und Bearbeitet por Marcel Thomann, Hildesheim, Georg Olms Verlagsbuchhandlung. 
ZwaLve, Willem - Sirks, Boudewijn (2012), Grunzüge der europäischen Privatrechtsgeschichte. Einfürung und Sachenrecht, Wien y otras, Böhlau, s.d.

\section{NORMAS CITADAS}

Code Civil des Français (1804), Édition originale et seule officielle, Paris, Imprimerie de la République.

Code Civil du Royaume de Sardaigne (1844), Paris, chez Joubert.

Codice Civile del regno d Italia (1865), Torino, Stamperia Reale, s.d.

Código Civil [de Cuba] (1989), Ley No 59, La Habana, Editorial de Ciencias Sociales.

Código Civil boliviano 1845), Sucre, Imprenta de Beeche y Compañía.

Código Civil boliviano (1885), Sucre, Tipografía de El Cruzado.

Código Civil de Chile (1856), Santiago, Imprenta Nacional.

Código Civil de Costa Rica (1887), San José, Imprenta Nacional.

Código Civil de España (1889), en la Gaceta de Madrid, № 207, de 26 de julio de 1889.

Código Civil de Honduras (1906), Tegucigalpa, Tipografía Nacional,.

Código Civil de la República Argentina (1870), Nueva York, Imprenta de Hallet y Breen.

Código Civil de la República Oriental del Uruguay (1893), Montevideo, imprenta de la Nación.

Código Civil del Distrito Federal y Territorio de la Baja California (1872), México, Tip. de J. M. Aguilar Ortiz.

Código Civil del Perú (1870), Lima, Imprenta del Estado.

Código Civil Portugués (1939), 4a ediciòn, Coimbra, Coimbra Editora.

Código Civil sancionado por el general Guzmán Blanco (1873/1973), Caracas, Imprenta Nacional; reimpresión Caracas. 